\title{
Tetrahedral DNA nanostructures for effective treatment of cancer: advances and prospects
}

Jianqin Yan ${ }^{1}$, Xiaohui Zhan ${ }^{2,3}$, Zhuangzhuang Zhang ${ }^{2,3}$, Keqi Chen ${ }^{4}$, Maolong Wang ${ }^{5}$, Yong Sun ${ }^{*}$, Bin He ${ }^{2,3}$ and Yan Liang ${ }^{1 *}$ (i)

\begin{abstract}
Recently, DNA nanostructures with vast application potential in the field of biomedicine, especially in drug delivery. Among these, tetrahedral DNA nanostructures (TDN) have attracted interest worldwide due to their high stability, excellent biocompatibility, and simplicity of modification. TDN could be synthesized easily and reproducibly to serve as carriers for, chemotherapeutic drugs, nucleic acid drugs and imaging probes. Therefore, their applications include, but are not restricted to, drug delivery, molecular diagnostics, and biological imaging. In this review, we summarize the methods of functional modification and application of TDN in cancer treatment. Also, we discuss the pressing questions that should be targeted to increase the applicability of TDN in the future.
\end{abstract}

Keywords: Tetrahedral DNA nanostructures, Functionalized modification, Intellectualization, Drug delivery, Tumor treatment

\section{Graphical Abstract}

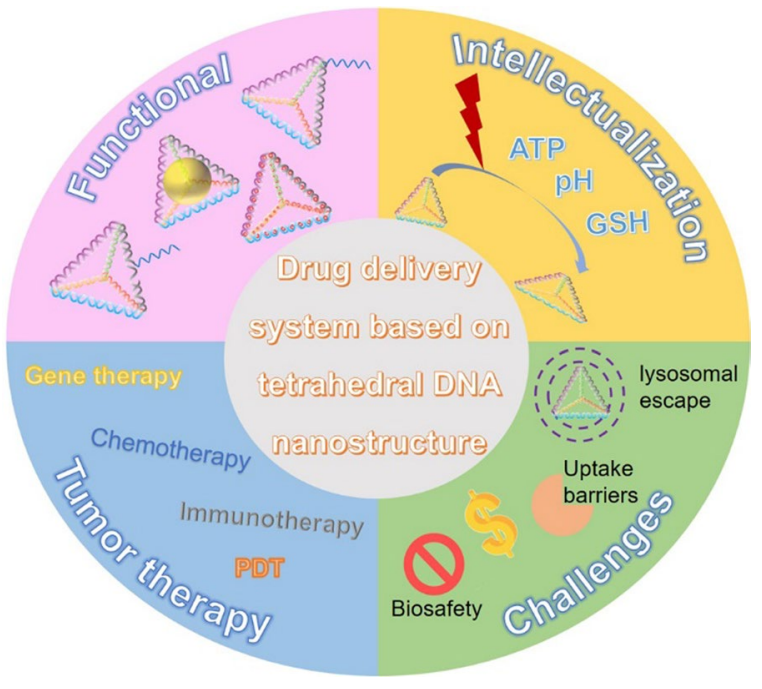

*Correspondence: sunyong@qdu.edu.cn; liangyan072@foxmail.com 1 Department of Pharmaceutics, School of Pharmacy, Qingdao University, Qingdao 266021, China

Full list of author information is available at the end of the article

\section{Introduction}

A safe and effective drug delivery system is urgently required to treat tumor growth, multidrug resistance, metastasis, and recurrence in cancer treatment. original author(s) and the source, provide a link to the Creative Commons licence, and indicate if changes were made. The images or other third party material in this article are included in the article's Creative Commons licence, unless indicated otherwise in a credit line to the material. If material is not included in the article's Creative Commons licence and your intended use is not permitted by statutory regulation or exceeds the permitted use, you will need to obtain permission directly from the copyright holder. To view a copy of this licence, visit http://creativecommons.org/licenses/by/4.0/. The Creative Commons Public Domain Dedication waiver (http://creativeco mmons.org/publicdomain/zero/1.0/) applies to the data made available in this article, unless otherwise stated in a credit line to the data. 
Multiple studies have been conducted to design and develop broad-spectrum of theranostic nanoplatforms to address this issue. The ideal nano-drug delivery system (NDDS) should simultaneously fulfill the following critical functions: (1) protect drugs from enzymatic degradation in vivo, (2) cross various physiological barriers, (3) provide accurate and controllable drug release, (4) reduce toxic and adverse effects of the delivered drug, (5) exhibit good biocompatibility and safety to the human body. Currently, multiple NDDSs are available, including organic nano-carriers such as liposomes $[1,2]$, polymeric micelles $[3,4]$, dendrimers $[5,6]$, metallic nanomaterial $[7,8]$ and inorganic nanoparticles like carbon nanotubes $[9,10]$, mesoporous silica [11], etc. [12, 13]. Although a variety of NDDSs have been used clinically, their heterogeneity, low biocompatibility, and low drug delivery efficiency limit the applications in cancer therapy. Therefore, it is important to increase the therapeutic index of drug delivery systems by developing innovative NDDSs with high clinical performance.

Deoxyribonucleic acid (DNA) is a biological macromolecule composed of four different deoxynucleotide monomers, which form supercoil structure by the complementary pairing of the basic group, thereby creating one the most vital biomolecules in the body [14]. The unique property of DNA molecules provides DNA nanomaterials unparalleled merits, including outstanding biocompatibility, good resistance to acidic and alkaline environment precise and adjustable structural control, and relatively straightforward computer-aided design of structure and function [14-17]. Compared with traditional NDDSs, the DNA nanotechnology is bringing revolutionary changes to the development of NDDSs for tumor treatment.

Tetrahedral DNA nanostructure (TDN) is a pyramidal three-dimensional nanostructure formed by the complementary pairing of four single-stranded DNA [14, 18]. TDN has been proposed as promising drug carriers due to their high stability, biocompatibility, rich functional modification sites, suitability for different drugs and excellent cellular uptake rates [19-22]. In Scheme 1, this review focuses on the functional modifications of TDN, intelligent NDDSs construction, and the prospects of TDN-based drug delivery systems for tumor treatment.

\section{Functional modification of TDN}

Currently, TDNs are mainly used as duplexes and double bundles, among which the duplex TDNs are studied better. The functional modifications of TDN include fluorescent dyes [23-25], bioligand molecules [26], functional proteins [27], small molecule anticancer drugs [23], and even nucleic acid molecules [28], etc. (Table 1). According to the different positions of functional groups or

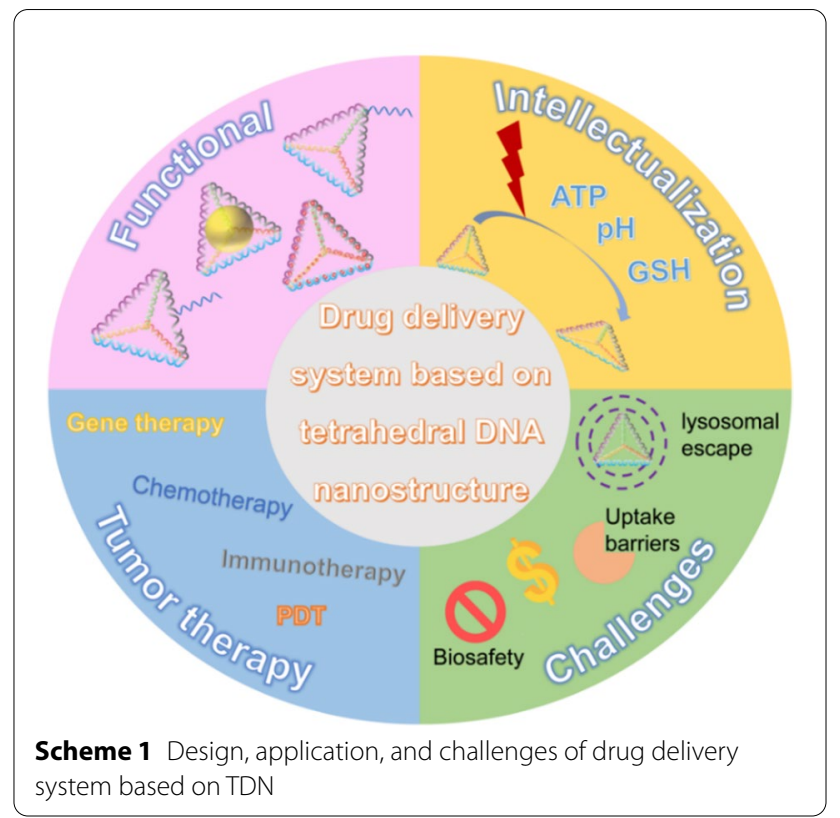

molecules in the TDN, there are mainly four key modification ways, including vertex modification, mosaic modification, capsule modification and cantilever modification (Fig. 1).

\section{Vertex modification}

Vertex modification refers to the modification of functional groups at the vertex position of a TDN, such as amino groups [59] or sulfhydryl groups [60, 61] used for TDN stabilization, specific sequence [59] or bioactive molecules used for molecular recognition, and azide groups [42] used for subsequent click reaction. In the process of vertex modification, functional groups are modified at the $5^{\prime}$ - or $3^{\prime}$-end of SS-DNA, then the TDN is formed by self-assembly to make the $5^{\prime}$ - or $3^{\prime}$-ends of four SS-DNA meet at the vertex of the tetrahedron. To enhance the therapeutic efficacy and targeting of breast cancer, Zhan et al. [34] attached the antimetabolite drug 5-fluorouracil (5-FU) to the TDN-based delivery system modified with a DNA aptamer (AS1411-T-5-FU). Anticancer reagent AS1411 could specifically bind to nucleolin, inhibit NF-KB signaling and reduce the expression of Bcl-2 [62-64]. Cell uptake research studies demonstrated that AS1411-T-5-FU has a better ability to target breast cancer cells than T-5-FU. At the same time, AS1411-T5-FU and 5-FU were compared in terms of inhibiting cell proliferation and related protein expression. Mitochondrial apoptotic pathway evaluation showed that AS1411T-5-FU could significantly upregulate the expression of Bax and caspase-3, down-regulate the expression of Bcl2 , and accelerate the process of apoptosis. Aptamer-based 
Table 1 TDN modifications and their applications for drug delivery

\begin{tabular}{|c|c|c|c|c|}
\hline Classification & Example & Modification & Application & Ref. \\
\hline \multirow[t]{9}{*}{ Small molecule } & Doxorubicin (DOX) & Mosaic & Chemotherapy & {$[23,29,30]$} \\
\hline & Paclitaxel (PTX) & Mosaic & Chemotherapy & {$[31]$} \\
\hline & Platinum drugs & Mosaic & Chemotherapy & {$[32]$} \\
\hline & Camptothecin & Cantilever & Chemotherapy & {$[33]$} \\
\hline & 5-Fluorouracil & Vertex & Chemotherapy & {$[34,35]$} \\
\hline & Methylene blue & Mosaic & Photodynamic therapy & {$[36]$} \\
\hline & Triphenylphosphine & Vertex & Mitochondrial targeting & {$[37]$} \\
\hline & Folate & Cantilever & Tumor targeting & [28] \\
\hline & Actinomycin D & Mosaic & Antibacterial treatment & [38] \\
\hline \multirow[t]{9}{*}{ Proteins or peptide sequence } & Cetuximab & Vertex & Immunotherapy & [39] \\
\hline & Cytochrome c & Capsule & Apoptosis & [27] \\
\hline & Streptavidin & $\begin{array}{l}\text { Capsule } \\
\text { Vertex }\end{array}$ & Immunotherapy & {$[40,41]$} \\
\hline & $\mathrm{D}^{-(\mathrm{KLAKLAK})_{2}}$ & Vertex & Mitochondrial targeting & {$[42]$} \\
\hline & Angiopep-2 & Cantilever & Receptor binding & {$[43]$} \\
\hline & Tumor-penetrating peptide & Vertex & Tumor penetrating & [44] \\
\hline & KillerRed & Cantilever & Photodynamic therapy & {$[45]$} \\
\hline & Nuclear localization signal (NLS) & Vertex & Nuclear targeting & {$[46-48]$} \\
\hline & Melittin & Capsule & Tumor treatment & [49] \\
\hline \multirow[t]{7}{*}{ Nucleic acid sequence } & AS1411 & Vertex & Tumor targeting & {$[50,51]$} \\
\hline & $\operatorname{sgc} 8 \mathrm{c}$ & Vertex & Tumor targeting & {$[52]$} \\
\hline & ZY11-targeting aptamer & Vertex & Tumor targeting & [53] \\
\hline & 17E DNAzyme & Vertex & Gene therapy & {$[53]$} \\
\hline & siRNA & $\begin{array}{l}\text { Cantilever } \\
\text { Vertex }\end{array}$ & Gene therapy & {$[28,30]$} \\
\hline & Antisense oligonucleotides & $\begin{array}{l}\text { Cantilever } \\
\text { Vertex }\end{array}$ & Gene therapy & {$[45,48,54]$} \\
\hline & CpG & Vertex & Immunotherapy & {$[15]$} \\
\hline \multirow[t]{3}{*}{ Other } & Gold nanoparticles & $\begin{array}{l}\text { Capsule } \\
\text { Vertex }\end{array}$ & Tumor treatment & {$[55,56]$} \\
\hline & Gold nanoclusters & Vertex & Bacterial detection & {$[38]$} \\
\hline & Anticancer metal complex & Mosaic & Tumor treatment & {$[57]$} \\
\hline
\end{tabular}

DNA materials have high recognition selectivity and specific binding to cancer cells, together with improving internalization efficiency. Yan et al. modified various numbers of $\mathrm{D}^{-}\left(\right.$KLAKLAK) ${ }_{2}$ (KLA) to the apex of TDN and loaded the anticancer drug doxorubicin (DOX) to achieve the mitochondria targeting [42]. Related experimental results indicated that KLA-modified TDN could effectively deliver DOX to mitochondria and induce apoptosis. 3KLA-TDN exhibited improved cellular uptake, mitochondria targeting, apoptosis pathway activation and in vitro anticancer efficacy (Fig. 2).

\section{Mosaic modification}

Mosaic modification means that functionalized molecules or groups are embedded in the double helix structure of TDN by conjugation, such as SYBR Green I [25] and other dyes [24] for fluorescent labelling, or anticancer drugs [23, 31-33, 42], and etc. DOX inhibits tumor growth by inserting DNA double strands to interfere with macromolecular biosynthesis [65]. DNA nanostructures loaded with DOX have the advantages of targeted delivery, response release, reduction of side effects and overcoming multidrug resistance, which are highly relevant for cancer and other diseases treatment. Dae-Ro Ahn's group [23] prepared the DOX@Td (DOX loaded on the side of the DNA tetrahedral double helix by physical conjugation method) as a carrier for drug delivery analysis. By exploring the uptake mechanism of free DOX and the interaction of p-glycoprotein (P-gp) with cell membranes, it is found that DOX@Td entered cells through endocytosis and effectively overcomes multidrug resistance. Liu et al. [31] built a TDN drug delivery system loaded 
(A)
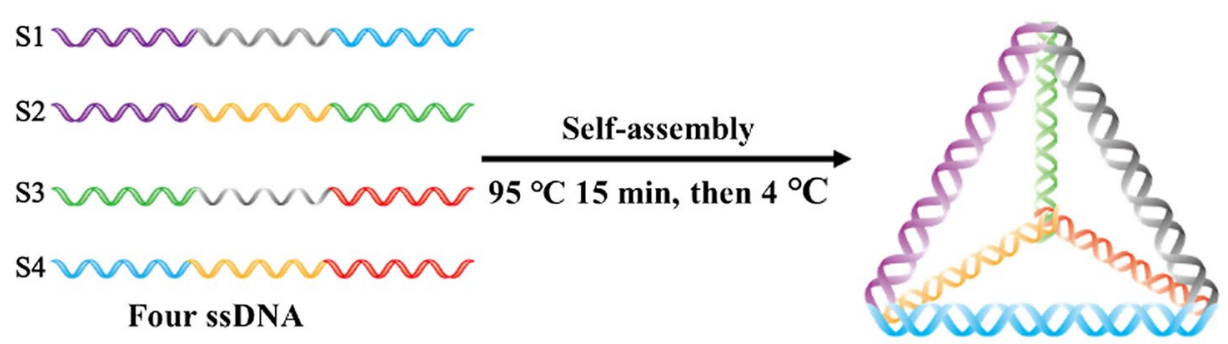

(B)
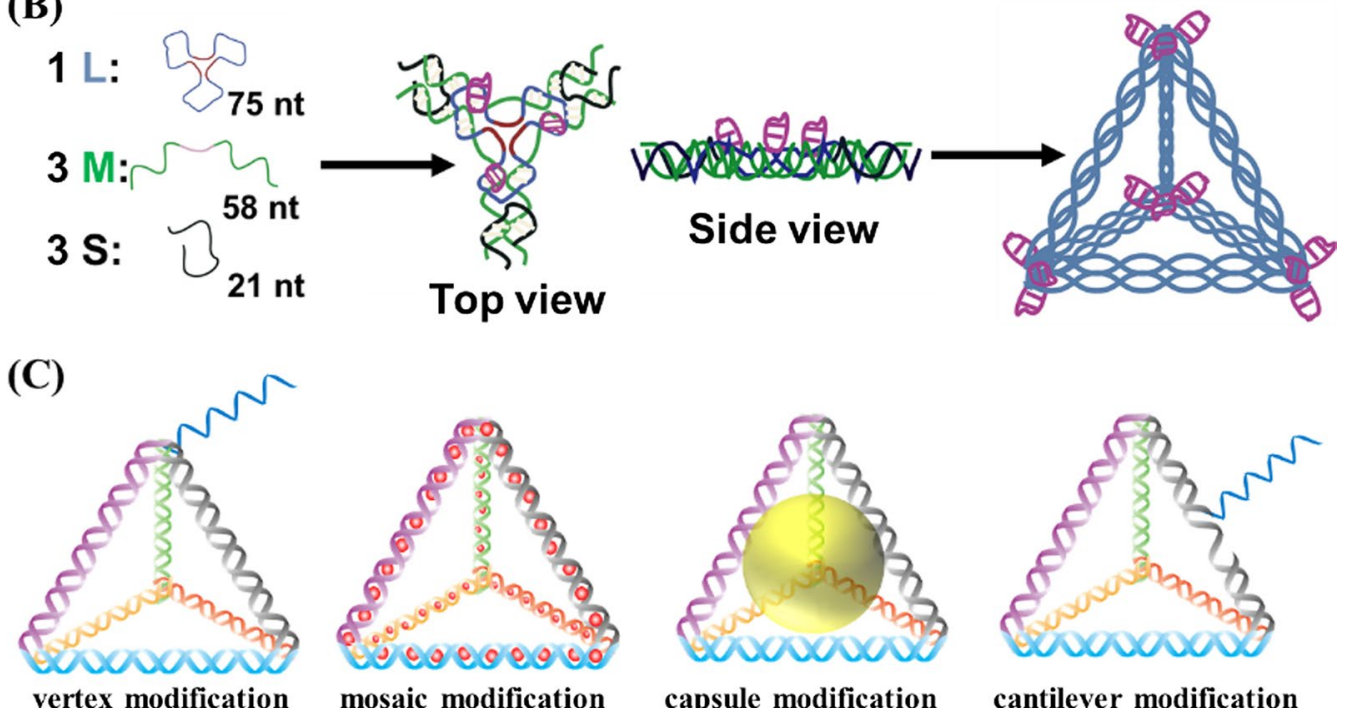

capsule modification

cantilever modification

Fig. 1 The schematic depicts TDN self-assembly (A) and double-bundle TDN [58] (B). C The key functional modifications of TDN are shown

with PTX (PTX/TDN). PTX/TDN were efficiently transported into A549/T cells, avoiding drug efflux pumps because of the caveolin-dependent and exocytosis pathways. And PTX/TDN could significantly inhibit the proliferation of multidrug-resistant and wild-type cells. TDN may act as P-glycoprotein (P-gp) inhibitor, down-regulating the expression of mdr-1 gene and $\mathrm{P}$-gp.

\section{Capsule modification}

Capsule modification involves wrapping functionalized molecules in a caged structure inside TDN. Turberfield et al. [27] estimated that the central cavity of the tetrahedron can accommodate a sphere with a radius of about $2.6 \mathrm{~nm}$. They bound cytochrome $C$ to the $5^{\prime}$-end of oligonucleotide and changed the sequence of oligonucleotide to regulate the position (internal or external) of cytochrome $\mathrm{C}$ relative to the TDN. This design could be applied to initiate an apoptotic protease cascade. Mao et al. prepared the nanocomplexes with a class of coreshell structure by encapsulating gold nanoparticles in DNA cages [66]. Such complexes have promising application prospects in tumor treatment with photothermal, photodynamic and immunotherapeutic methods [67-69].

\section{Cantilever modification}

Cantilever modification involves suspending functional molecules or groups on the side arms of TDN. For example, the intersection of the $5^{\prime}$ and $3^{\prime}$ ends of the SS-DNA is on the edge (middle or other non-vertex) of the TDN by designing the base sequence of SSDNA, where the $5^{\prime}$ or $3^{\prime}$ ends without complementary pairing extend outwards for modification of functional molecules. Utilizing the hydrophilicity and editability of DNA nanostructures, Tian et al. [43] modified TDN with angiopep-2 (ANG-TDN), which showed a strong binding to the low-density lipoprotein receptor-related protein-1 (LRP-1) of glioma and the blood-brain barrier (BBB) cells. ANG-TDN was found to be stable in the serum for at least $12 \mathrm{~h}$, indicating high stability. The modification of angiopep-2 could efficiently improve the uptake of TDN by brain capillary endothelial cells and Uppsala 87 malignant glioma (U87MG) cells. Meanwhile, experiments in vitro and in vivo showed 

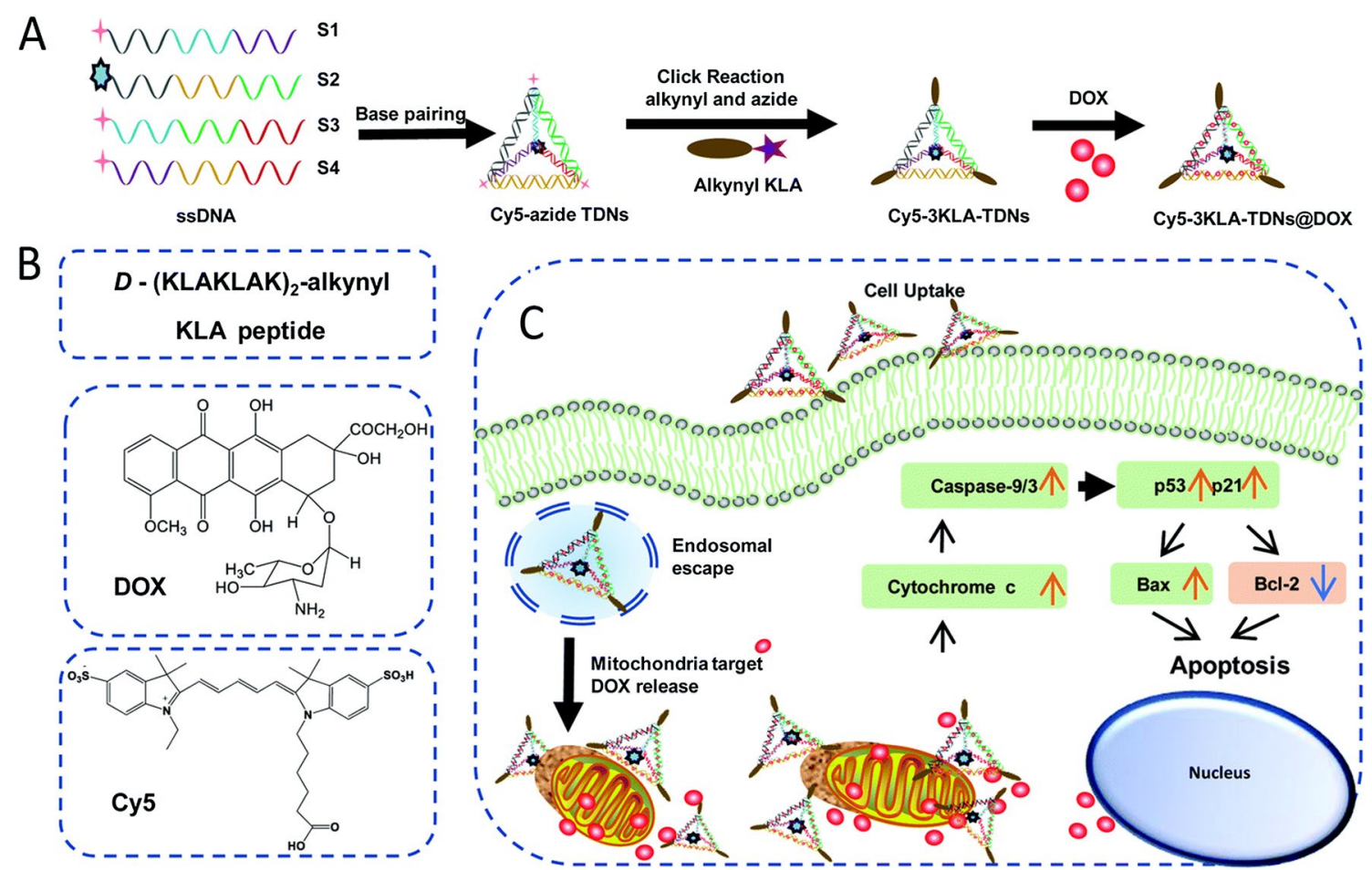

Fig. 2 Schematic design of mitochondria-targeted 3KLA-TDN/DOX treatment for the breast cancer (Reprinted with permission from [42]. Copyright 2020, Royal Society of Chemistry)

that ANG-TDN could effectively cross the blood-brain barrier and precisely target U87MG human glioblastoma xenograft in nude mice. It had also been reported that siRNA or chemotherapy drugs can be loaded to TDN by cantilever modification [28, 33], and that exchanging the hydrogen bonds of branched DNA structures for covalent bonds can further enhance TDN stability.

Although different biomolecules had been linked to TDN for drug delivery, biological detection [59, 61, 70] and imaging applications [71, 72], it is still unclear whether TDN may carry molecules beyond its size and molecular weight. If different biomolecule is modified on the vertex or arm of TDN, the subtle balance of conformational flexibility of the TDN could probably be destroyed, resulting in the altered stability, rigidity, and geometric structures of obtained assemblies [73]. It is known that the size, shape, and number of charges of DNA nanostructures will affect their cellular uptake pathways, intracellular transport, and destination [74]. Whether attaching a nucleic acid with complex secondary structure will interfere with the TDN uptake process needs to be further explored [20], and choosing smaller sizes and charges is promising.

\section{Programmable TDN}

The traditional NDDSs is generally not programmable, resulting in the drug being released once entering the organism, and the distribution in the organism is not selective, and eventually relatively large side effects. Only a few drug carriers could reach the tumor tissues through the enhanced permeability and retention (EPR) effect, but the drug has low bioavailability and poor efficacy. With the increasing understanding of tumor microenvironment, researchers have proposed building intelligent NDDSs to enhance antitumor efficacy. Because of the differences in the microenvironment of the tumor and normal tissues, the release of anticancer drugs at tumor sites can be controlled to improve their bioavailability and efficacy, meanwhile reduce their toxic and side effects on the non-affected organs. Programmability of TDN implies that the structure can recognise tumor microenvironment and target it. Programmable TDNs can recognize changes in $\mathrm{pH}[25,75]$, excitation light wavelength [76], various components and their concentrations [77] to initiate modifications that meet different application requirements. 


\section{pH sensitive TDN}

Wang et al. [78] monitored the changes of the TDN and the i-motif connected TDN at $\mathrm{pH} 8.5$ and $\mathrm{pH}$ 4.5. The results showed that not only the orientation of the i-motif structure could be modulated electrically to produce an "open and close" signal, but the structure of TDN and DNA double helix would also change. Another experiment showed that the TDN structure loaded with DOX significantly increased the drug release under acidic conditions, which is related to the structural metamorphosis of DNA material [42, $44,53]$. Therefore, we speculate that the structure of the TDN deforms in an acidic buffer. At the same time, TDN can be purposefully modified to obtain pH sensitivity. Keum et al. [75] demonstrated a pH-dependent conformational change of DNA pyramids by introducing i-motif sequences (Fig. 3A). Their results demonstrated that the i-motifs can regulate the DNA pyramids assembly and disassembly and are suitable for in situ encapsulation and controlled release of proteins (enhanced green fluorescent protein, EGFP) by changing the physiologically relevant $\mathrm{pH}$. Liu et al. [79] developed a strategy to reversibly assemble or disassemble DNA nanocages based on $\mathrm{pH}$ sensitivity. The pH-sensitive DNA tetrahedron was based on the DNA three-point star motif, which indicated that the DNA complex changed the structure between a single motif in a neutral solution ( $\mathrm{pH} 8.0)$ and a tetrahedron in an acid solution ( $\mathrm{pH}$ 5.0) to achieve the disassembly and disassembly of TDN. Kim et al. [80] proposed a method to encapsulate enzymes in TDN, which could change its conformation according to $\mathrm{pH}$. TDN encapsulated the enzyme to avoid the degradation of the protein, reduce the binding of the enzyme and antibody, and reduce its activity. Due to the existence of i-motif-forming sequence and $\mathrm{pH}$ sensitivity, the conformation of TDN is changed, which promotes the enzyme to contact with other molecules. This approach can be further extended to reversible regulation of cell function through the $\mathrm{pH}$-dependent activity control of enzymes. Such smart DNA nanostructure can potentially capture and release cargos on demand.

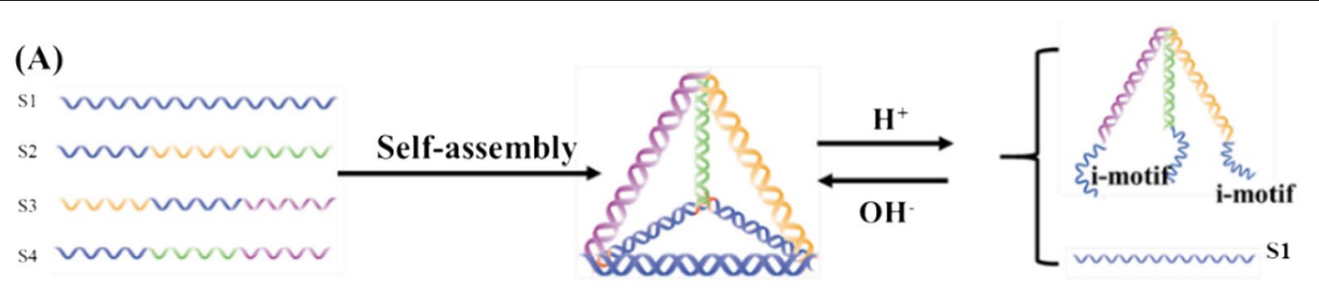

(B)

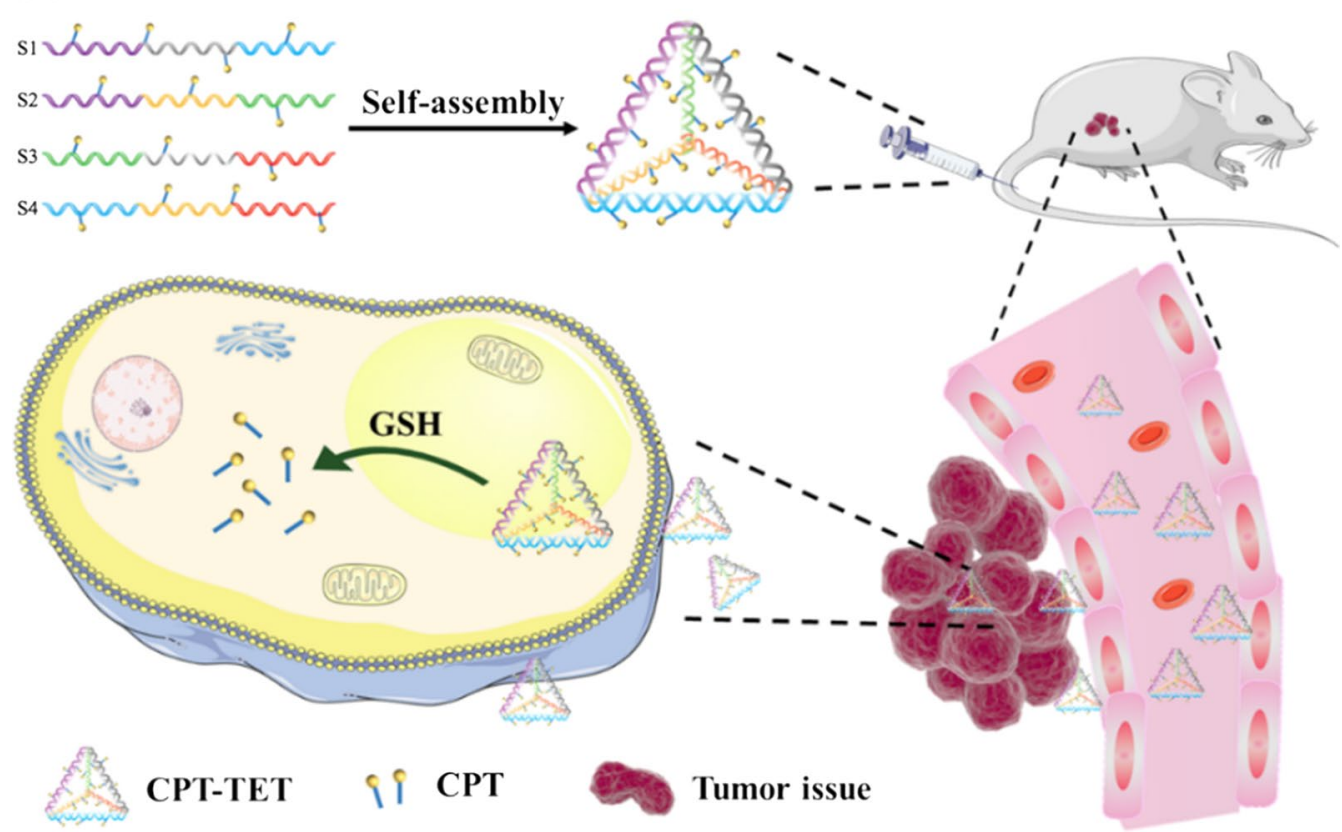

Fig. 3 Programming the TDN. A Schematic shows pH-triggered conformational changes of TDN modified with an i-motif. B The synthetic route and delivery process of CPT-loaded TDN as precise and responsive nanomedicine 


\section{GSH responsive TDN}

Disulfide linkage, due to its stable and covalent linkages, have also been employed to control the DNA structure [81]. Endo et al. used disulfide linkage modified on the phosphorus atoms outside the DNA chain to connect two single DNA strands for branched DNA structures (XLDNA) [82]. Two XL-DNA and complementary strands could self-assemble into multibranched DNA nanostructures. Glutathione (GSH) is an important reducing agent in cells and could efficiently cleave disulfide bonds. Therefore, multiple strategies were proposed for linking chemical compounds to DNA nanostructures with disulfide bonds. Zhang et al. [33] reacted phosphorothioate-modified DNA with carbonyl bromide-modified camptothecin (CPT) to form disulfide bonds (Fig. 3B). The DNA sequences grafted with $\mathrm{CPT}$ were then assembled into TDN structures using programmable DNA nanotechnology. The system could adjust the hydrophilicity of DNAdrug conjugates by regulating the amount and location of CPT modified on DNA to maintain its water solubility and molecular recognition ability. Programmable DNA nanotechnology could realize precise self-assembly of drug-containing TDN with stimulus-response properties and enhance antitumor efficacy in vivo and in vitro.

\section{Light responsive TDN}

Han et al. [76] have successfully constructed a photon controlled TDN with azobenzenes. The shape of TDN can be controlled by alternating irradiation at different wavelengths. The results showed that the two isosceles of TDN were approximately $7 \mathrm{~nm}$ and the bottom edge was $11 \mathrm{~nm}$ before UV irradiation. After exposure to UV irradiation, some TDN contracted, causing the bottom side of the triangle to shrink to $4 \mathrm{~nm}$. Triggering threedimensional changes and promoting the release of cargos (such as proteins or other macromolecules) encapsulated in TDN allows for, precise temporal and spatial control. Quet al. [83] have successfully manufactured NIRresponsive upconversion-nanoparticle with Au20-Au30 centered in the nanoparticles tetrahedron (UAuTe) using DNA self-assembly (Fig. 4). The tetrahedron selectively targeted aging cells and induced the apoptosis of senescent cells by exposing Granzyme B under NIR light. When the $\beta$-2-microglobulin antibody (anti-B2MG) on Au NP recognizes senescent cells, applying near-infrared light (NIR) destroys the boronic ester linkage and induces the disassembly of UAuTe. In the presence of perforin, Granzyme B can induce target cell apoptosis via intrinsic adjustment. Compared with Granzyme B alone, the UAuTe could not only control the release of Granzyme B through NIR-responsivity, but also synergistically target the senescent cell and activate the Granzyme B without

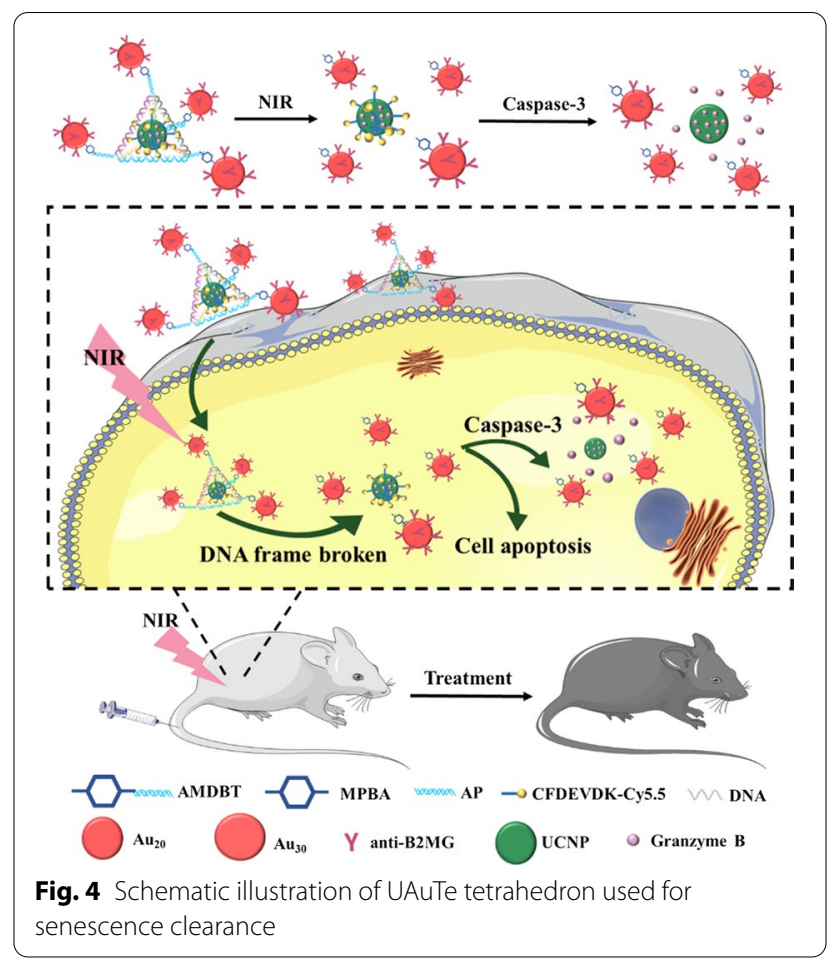

the need of perforin. The NIR-responsive TDN provides a practical strategy for aging and age-related diseases, and it also provides a potential for tumor therapy.

\section{ATP responsive TDN}

ATP-responsiveness is advantageous for the adjustment of DNA decomposition. ATP is the main energy molecule in the cells, and its concentration in the extracellular microenvironment $(<0.4 \mathrm{mM})$ is much lower than that in the intracellular microenvironment $(1-10 \mathrm{mM})$. Moreover, the ATP concentration in tumour cells is higher than that in normal cells [84]. Based on these two differences, ATP-responsive DNA nanostructure DDSs can be designed [85]. Aptamer-ATP complexes are formed through conformational changes which promote the decomposition of DNA nanostructures and the release of drugs in ATP-rich environments [86]. ATP aptamers are commonly found in ATP-responsive DNA nanostructures because of their highly specific and sensitive properties [87]. Pei et al. [77] developed a DNA tetrahedron that showed a corresponding structural switching response to external stimuli (Fig. 5A). By adding dynamic sequences (i-motif, anti-ATP aptamer, T-rich mercuryspecific oligonucleotide) to DNA tetrahedra, the configuration of the tetrahedron could be changed in response to the input of a specific target (protons, ATP, and mercury ions). These TDN provide new opportunities to "logically" control the release of drugs into cells. 
(A)

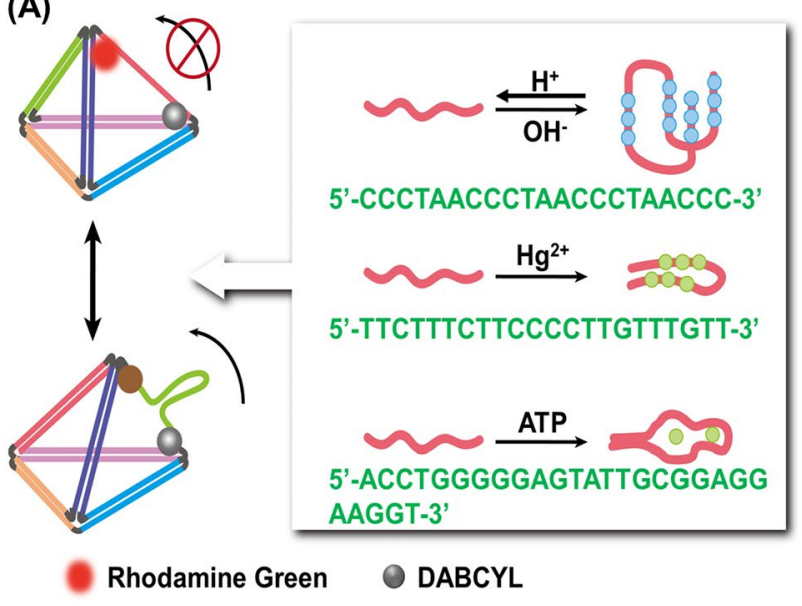

(B)
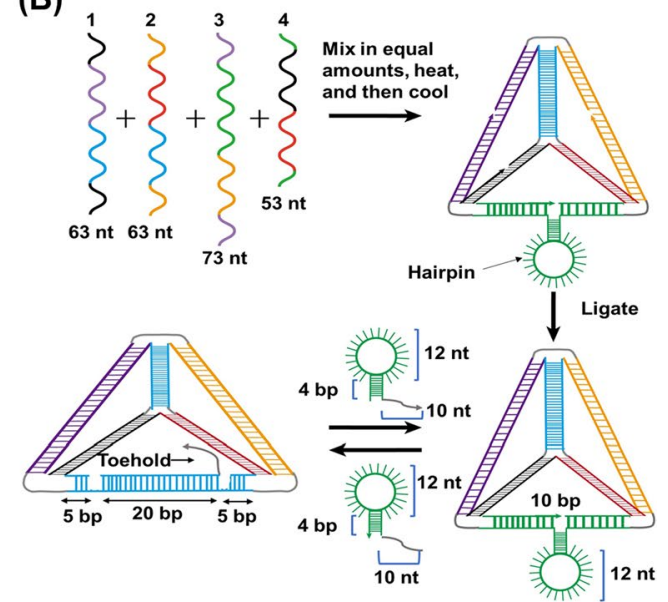

Fig. 5 Programming the TDN. A The scheme demonstrates the TDN changes in response to the introduction of specific targets. Reprinted with permission from [77]. B Dynamic control of the TDN structure by specific sequences (Reprinted with permission from [89])

\section{Dynamic control of the TDN structure}

Abi et al. [88] showed that the reconfiguration switching of the tetrahedral structure could be efficiently realized under high ionic strength conditions. Goodman et al. [89] also studied and realised the dynamic control of a TDN structure designed with hairpin loops through specific nucleic acid sequences (Fig. 5B). In addition, the ability to reversibly switch the surface porosity of the nanocage helped to achieve the controllability of material transport in and out of the nanocage, which is a desired characteristic of a DDS. Zhang et al. [90] could reversibly switch the surface pore sizes of TDN by controlling two three-point-star motifs.

The response of TDN to the environmental stimulus to achieve different application requirements is the current research hotspot. Drug delivery to different types of cells requires different DDSs based on the physicochemical properties. These changes in conditions or components are stimulus factors and provide energy and impetus for structural changes. When these conditions are changed, the structure of TDN will change spontaneously and intelligently. Owing to the unique physical and chemical properties of DNA, the precisely modified sequences (i.e., i-motifs) can be embedded into the branched DNA endowed materials with different characteristics. The structure and size of DNA nanomaterials determine their cellular uptake pathways [74]. Whether these modifications affect their cellular uptake efficiency is still unknown. At the same time, the unbalanced stress distribution on the edges of the TDN corresponding to the DNA strings would result in the altered stiffness of the tetrahedron [20], and its mechanical properties and serum stability may change. These issues require further attention in future studies.

\section{Application of TDN in tumor therapy Chemotherapy}

Chemotherapy has a long history of clinical application and a wide range of indications, and it is currently one of the main methods for treating tumours. Most chemotherapeutic drugs are fat-soluble cellular drugs with different mechanisms of action, including: (1) affecting the chemical structure of DNA, such as cisplatin [91], (2) inhibition of nucleic acid synthesis, such as DOX and 5-fluorouracil [65, 92]; (3) interfering with DNA replication, such as camptothecin drugs [93]; and (4) interfering with the synthesis of tubulin during mitosis, such as paclitaxel [94]. At present, a variety of DDSs based on TDN have delivered the above-mentioned drugs to different organelles, such as mitochondria [37, 42] and nuclei [46], achieving excellent antitumour (even drug-resistant) effects both in vivo and in vitro. To solve the serum stability problem of natural ${ }_{D}$-sugar-based Td, Kim et al. prepared a mirror form of natural $\mathrm{D}_{\mathrm{D}}-\mathrm{Td}(\mathrm{L}-\mathrm{Tds})$ and used it to load DOX [29]. The results showed that ${ }_{\mathrm{L}}$-Tds could selectively deliver anticancer drugs to tumour cells and enhance cell/tissue penetration. At the same time, the mirror structure has an important effect on the pharmacokinetics and biodistribution of DNA nanostructures. In addition, we demonstrated that linking redox-responsive polyethyleneimine to TDN improve their serum stability by preventing enzymatic degradation, allow for tumor cell/tissue penetration, and overcome multidrugresistant cancer [95] (Fig. 6). 


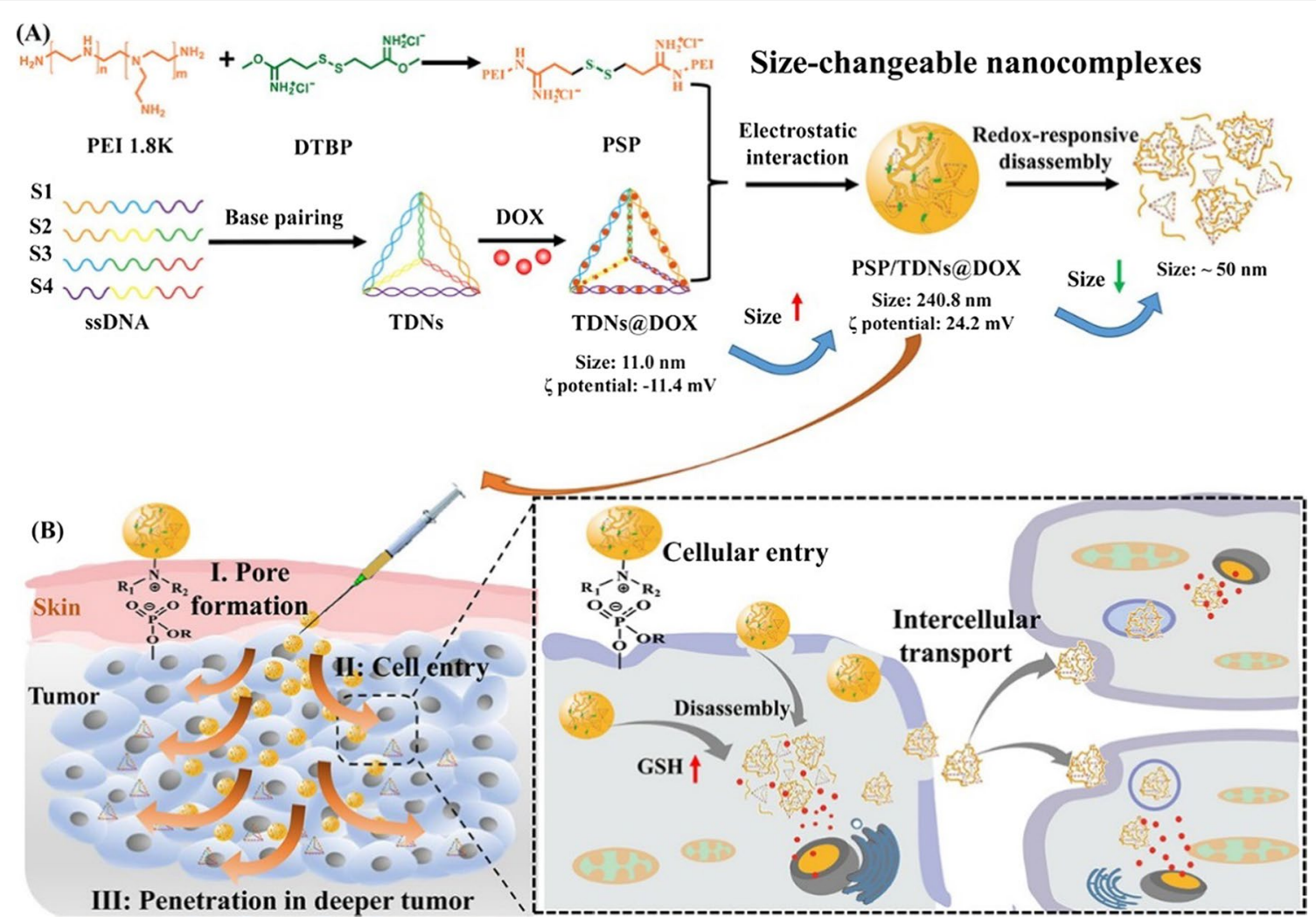

Fig. 6 Schematic shows the strategy for modifying TDN with the redox-responsive polyethyleneimine. The presented functionalization method improves tumour cell/tissue penetration for treating multidrug-resistant tumours (Reprinted with permission from [96]. Copyright 2021, Elsevier)

Compared with duplex TDN, the double-bundle TDN invented by Mao et al. [58, 96] has better rigidity and stability, more modified binding sites and higher drug loading efficiency. Therefore, the double-bundle TDN has great potential as an efficient drug delivery system. $\mathrm{Wu}$ et al. [32] embedded the platinum drug 56MESS into a double-bundle TDN and coupled the anti-epidermal growth factor receptor (anti-EGFR) nanobody to the TDN to achieve multi-drug combination therapy for tumor (Fig. 7). The nanostructure could block EGFR signal transduction and exhibited excellent selectivity for cells with elevated EGFR expression, which exhibited significant anti-tumor activity without obvious systemic toxicity. In addition, drugs such as 5-fluorouracil, camptothecin and paclitaxel are loaded on TDN in different modified ways to achieve effective treatment of tumors [31, 33, 34]. The above-mentioned multifunctional DDS provides a new approach for tumor targeted chemotherapy and provides practical guidelines for enhancing reproducibility and reliability for the combined delivery of other functional components such as proteins.

\section{Photodynamic therapy}

Photodynamic therapy (PDT) is a minimally invasive therapy that has been clinically approved for cancer treatment with selective cell toxicity [97]. PDT has three main components: a light of specific wavelength, a photosensitising (PS) drug and oxygen. During the treatment process, the three interact to produce cytotoxic reactive oxygen species (ROS), which kill tumor cells through apoptosis or necrosis [98-100]. Typical photosensitizers, such as porphyrin derivatives and carbazole derivatives, have strong hydrophobicity and are easy to aggregate in aqueous solution, thus affecting the therapeutic effect [98, 101]. To this end, the researchers have developed various DNA nanostructures for the efficient delivery of photosensitizers. Kim et al. [36] employed TDN as a carrier for the intracellular delivery of methylene blue (MB) by taking advantage of the DNA binding property of the MB (MB@Td) and demonstrated photo-induced cytotoxicity (Fig. 8). Experimental results showed that sixteen molecules of MB could be loaded on TDN and delivered into cells without affecting the property of MB. The photo-induced cytotoxicity was virtually proportional to 


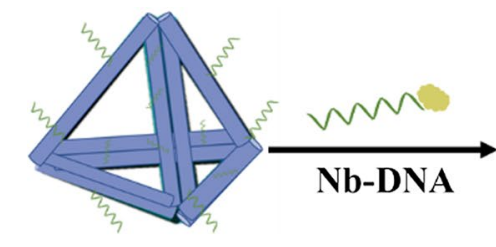

TET

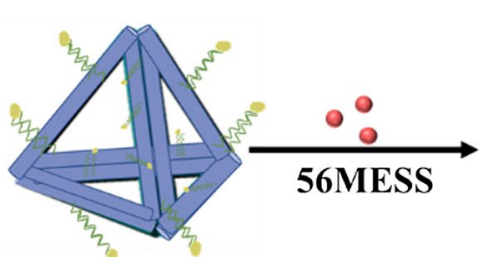

Nb-TET

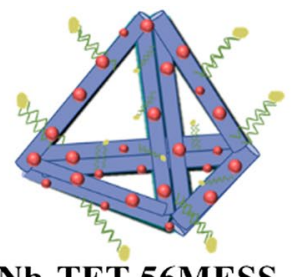

Nb-TET-56MESS

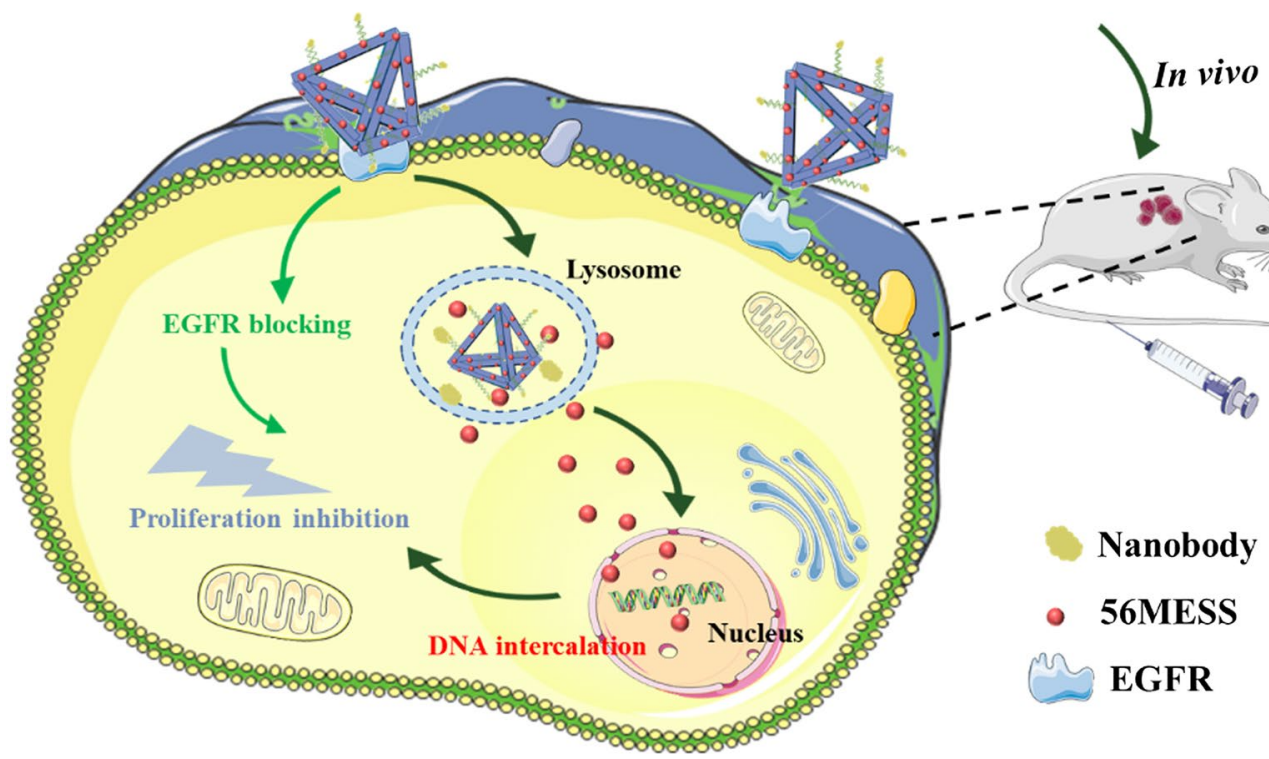

Fig. 7 Schematic illustrates the nanobody-conjugated double-bundle TDN for targeted platinum drug delivery

the amount of the intracellularly delivered $\mathrm{MB}$ in vitro. In addition,MB@Td produced an effective treatment effect of PDT and had a good tumor inhibition effect in vivo. TDN is expected to have superior properties for delivering PDT agents in future tumor therapies.

\section{Immunotherapy}

In recent years, tumor immunotherapy has attracted increasing attention as one of the most promising strategies for cancer treatment. In contrast to traditional radiotherapy and chemotherapy, immunotherapy use the host immune system to kill tumor cells and effectively inhibit tumor metastasis and recurrence. Cytosinephosphate-guanine oligodeoxynucleotides (CpG ODN) can stimulate dendritic cells, B cells, macrophages to produce pro-inflammatory cytokines including tumor necrosis factor- $\alpha$ (TNF- $\alpha$ ), interleukin-6 (IL-6), and activate the innate immune system by interacting with Toll-like receptor 9 (TLR9) to enhance anti-tumor activity [102-104]. The effectiveness of immunotherapy largely depends on the dose of the immunomodulatory sequences, and one of the critical problems is to increase the dose of agent in a single drug carrier. Functionalized materials can elicit specific immunological responses to therapy by incorporating special motifs with immunomodulatory activity. Therefore, $\mathrm{CpG}$ ODN, as a safe and effective vaccine adjuvant, has been widely used in basic research and clinical trials of tumor immunotherapy [105]. In recent years, the use of DNA nanostructures as $\mathrm{CpG}$ delivery vehicles has been explored. Owing to their inherent compatibility, CPG-rich sequences can be easily integrated into DNA nanostructures to enhance their stability and targeting. Liu et al. [40] used TDN to co-transport $\mathrm{CpG}$ and streptavidin (as a model antigen) to continuously induce a stronger immune response, and TDN alone did not elicit an immune response. Fan et al. [15] used TDN functionalized with unmethylated cytosine-phosphate-guanine $(\mathrm{CpG})$ motifs for the immune activation of macrophage-like RAW264.7 cells (Fig. 9). The results of this study showed that the functionalized TDN are internalized by the cells and remain largely intact for $8 \mathrm{~h}$, thereby inducing ample release of cytokines, including tumour necrosis factor (TNF- $\alpha$ ), interleukin-6 (IL-6), and interleukin-12 (IL-12). Meanwhile, the multivalent $\mathrm{CPG}$ motifs also significantly enhanced the immunostimulatory effect of TDN. These studies have expanded the significantly of TDN in tumor immunotherapy and demonstrated the potential of 

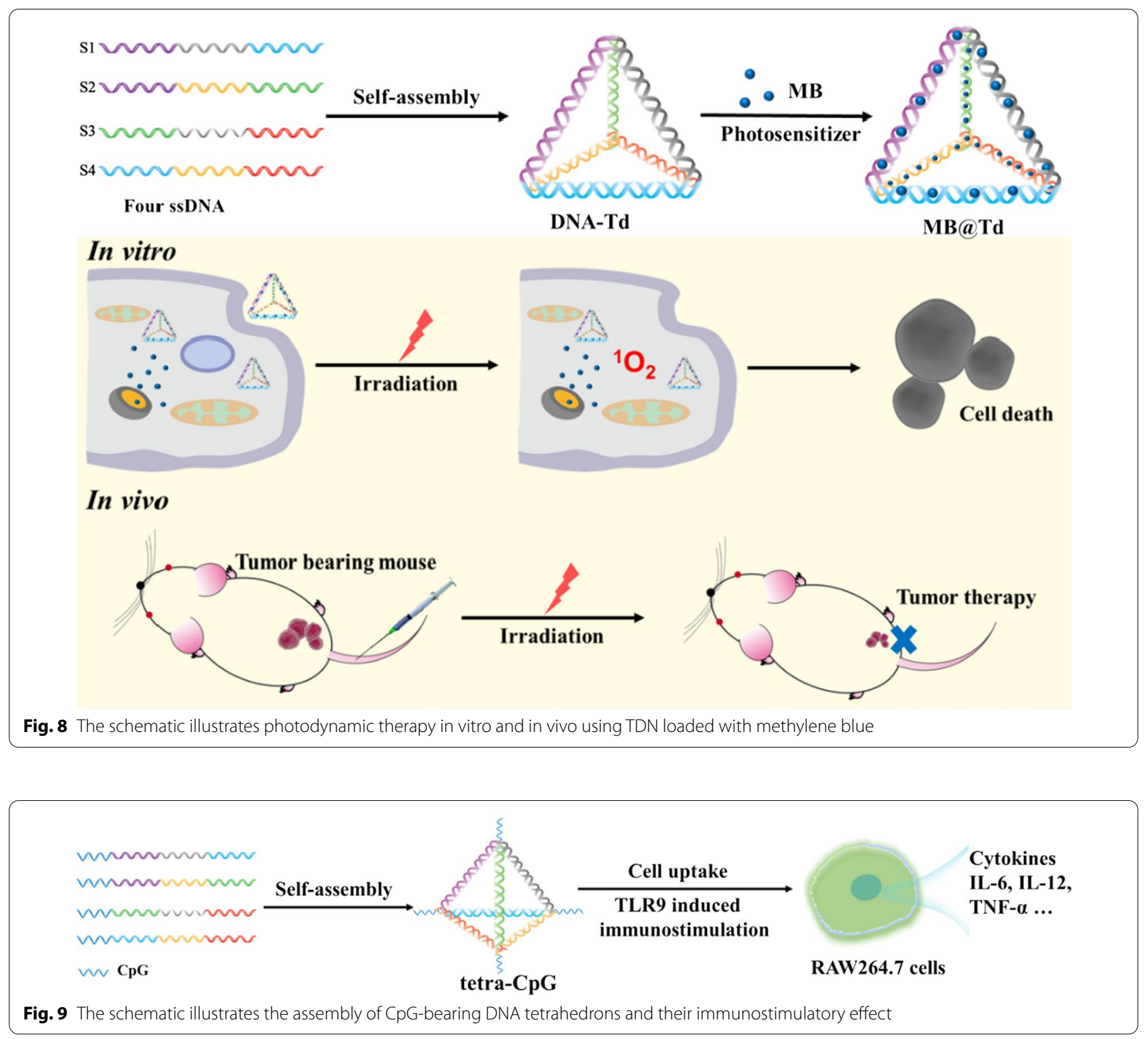

further research in this direction. TDN can serve as a carrier for a variety of therapeutic agents and as stable vehicles for the target-delivery to immune cells or tumor cells.

\section{Gene therapy}

With the continuous development of gene manipulation technologies such as gene editing and gene silencing, multiple approaches were proposed for up-downregulating the expression of target genes that are specific to the disease treatment. In recent years, gene therapy has gained increasing attention in the field of tumor treatment. A series of tumor-related genes, such as Ras, Myc and polo-like kinase 1 (PLK1), have been verified and used in clinical trials [106]. However, gene therapy drugs are not easily taken up by cells and are relatively unstable during circulation. Therefore, the success of gene therapy largely depends on the safety and effectiveness of gene delivery vehicles. Gene therapy vectors mainly include viral vectors and non-viral vectors. The use of viral vectors is limited because of possible insertion mutagenesis and immunogenicity [107]. Therefore, a major challenge for gene therapy is the design of non-viral vectors to achieve safe and efficient gene delivery. From the application point of view, TDN are advantageous as non-viral vectors owing to their inherent physiological effects, biocompatibility, and biodegradability. Due to the high loading capacity and high biocompatibility of DNA 
nanostructures, TDNs can be considered as non-viral vectors for effective targeted gene therapy.

Anderson's group applied TDN nanomaterials to deliver small interfering RNAs (siRNAs) into nude mice model with tumors to inhibit the expression of target genes for tumor treatment research [28]. In this study, siRNA was suspended on the side of the tetrahedron by complementary pairing, and the tetrahedron loaded with the siRNA was targeted to the lesion site through the ligand connected to the cancer cell receptor. The hydrodynamic size of the nanoparticle is approximately $28.6 \mathrm{~nm}$, which is favorable for cell uptake. DNA tetrahedron has a significant tumor-targeting ability after folic acid modification. Because the space direction of siRNA transported by TDN and the location and density of tumor-targeted ligands could be precisely controlled, the function of gene silencing could be maximized. Thus, tetrahedral DNA materials can be used for not only silencing the tumor target genes by delivering siRNA, but can also be used as a reference in the treatment of other diseases.

Despite the emerging evidence demonstrating exciting achievements, there is still much room for further development of TDN. As single treatment no longer meets the high demands for the efficiency of tumor treatment, the combined application of multiple treatments become a promising research field. Zhong et al. [53] reported a nanocarrier consisting of TDN, ZY11-targeting aptamer,
DOX and 17EDNAzyme to achieve synergistic chemogene cancer therapy (Fig. 10). In addition, the combined use of DOX and CpG could achieve chemo-immune combination therapy. Therefore, the applicability of traditional treatment methods can be further expanded by developing new strategies for tumor growth inhibition.

\section{Challenges and prospects}

TDN has decisive advantages that make them promising novel drug carriers. TDN can be synthesized easily, reproducibly, and has good biocompatibility and excellent performance. Through reasonable modification, TDN can efficiently incorporate chemotherapeutic drugs, nucleic acid drugs, imaging probes and etc., and exhibit good application potentials in drug delivery, molecular diagnostics, and biological imaging. However, TDN still have weaker sides such as poor enzyme resistance and insufficient ability to cross physiological barriers, including the lack of targeting, poor permeability in tumor tissues, and low cell entry efficiency. For efficient drug delivery, several roadblocks have to be removed before TDN can compete with existing drug carriers such as polymers, liposomes, and inorganic nanoparticles.

First, adverse factors such as enzymatic degradation and protein adsorption in the body can destroy the structural integrity of TDN, causing the untimely drug leakage and failure to reach the expected target site. He et al. and Lin et al. showed that packaging with polyethyleneimine

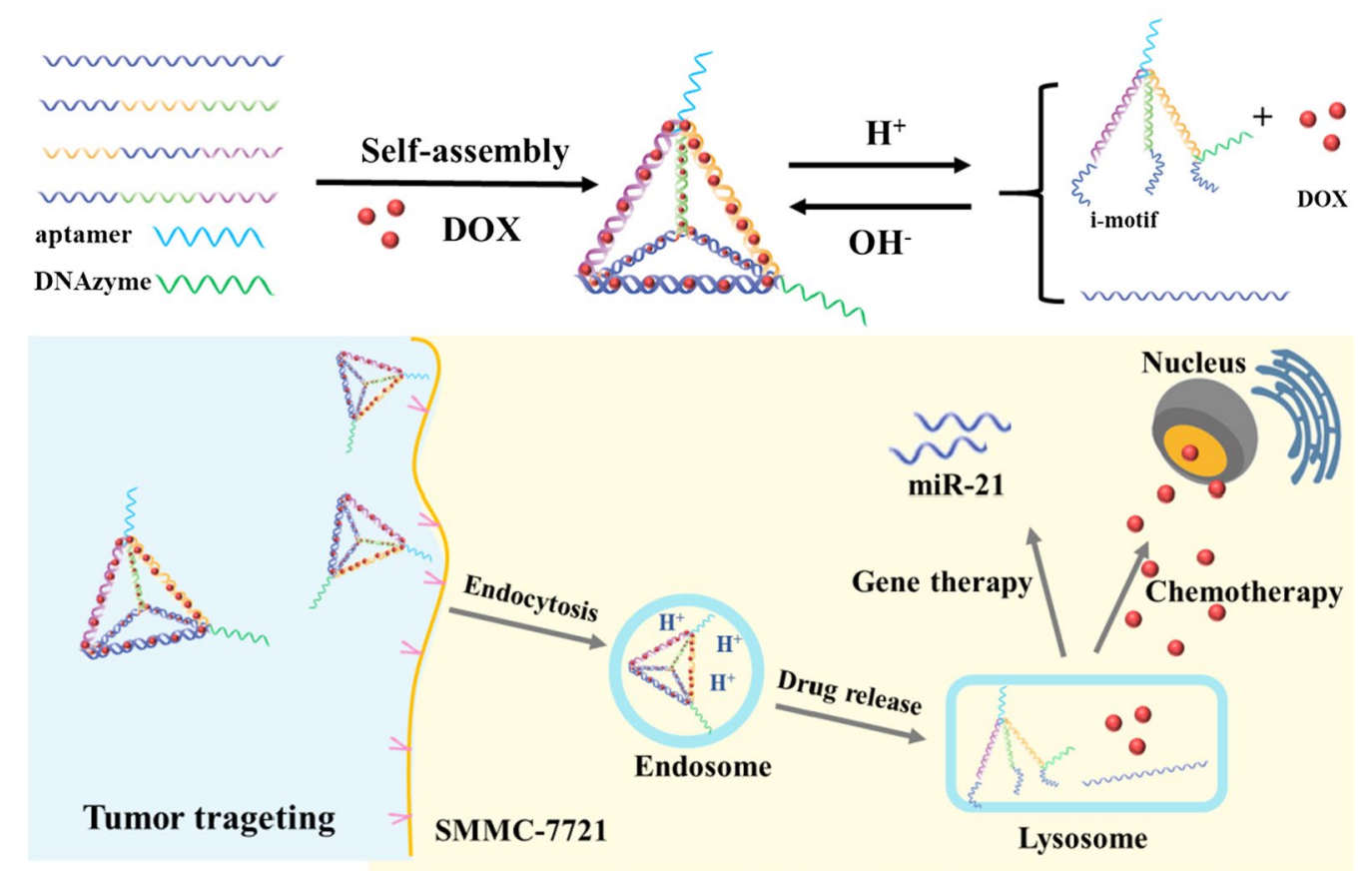

Fig. 10 The schematic illustrates synergistic chemo-gene therapy targeting cancer cells 
(PEI) or PEGylated protamine could significantly avoid TDN enzymatic hydrolysis, promote the cellular uptake and lysosomal escape of TDN [95, 108, 109]. Lin et al. also also demonstrated that multiple pathways, including micropinocytosis and caveolin- and clathrin-dependent endocytosis contributed to the endocytosis of PEI/TDN complexes. However, the toxicity or other adverse effects of these chemical modifications still need to be considered. For example, PEI $25 \mathrm{~K}$ has greater cytotoxicity [110], therefore, it is urgent to explore better solutions.

Second, the lysosomal escape ability of TDN needs to be further improved. Although DNA nanostructures could enter cells better than oligonucleotide, Fan's group found that TDN was trapped in lysosomes after entering cells [46], prompting the collapse of TDN and the release of drugs. Some antitumor drugs, whose targets are not in the lysosome ( $\mathrm{pH}$ value about 4.5-5.5) [111] and are unstable under acidic conditions and release in lysosomes could make them less effective or inactivated. Their group modified the nuclear localization signal peptide (NLS) at the TDN vertex to synthesize NLS-TDN and endowed it with nuclear targeting capability, which helped the TDN escape from lysosomes and accumulated in the nucleus. Therefore, improving the lysosomal escape ability of TDN is particularly important for the maximising therapeutic effect of drugs. Furthermore, to expand the structural and functional diversity, a more refined design of the structure and introduction more kinds of stimulating components (such as metal-sensitive, and magnetic-sensitive components) are needed.

Third, there are still barriers that hinder the effective transportation of DNA nanostructures including TDN in the process of drug delivery, and the barriers include the blood-brain barrier and plasma membrane barrier. Fan et al. [46] confirmed that the entry of TDN into cells in a caveolin-dependent endocytosis pathway through a series of fluorescence imaging and biochemical experiments, which is a type of receptor-mediated endocytic pathway. However, these energy-dependent or receptorrecognized pathways cannot efficiently deliver DNA nanostructures, such as TDN. Therefore, it is particularly important to design TDN-based drug carriers that can effectively penetrate various physiological barriers, specifically target diseased tissues or cells, with little or no uptake by normal organs and cells [112].

Biosafety is another concern. Oligonucleotides are biodegradable and biocompatible. However, things may change when DNA is designed into nanostructures. The dynamic unstable state and thermodynamic stable state of nanostructures should conduct more in-depth research on the physical and chemical properties of TDN. The potential immunostimulatory properties of TDN must be systematically investigated before they can be used for clinical biological applications [113]. Meanwhile, research on the pharmacokinetics of TDN (in vivo circulation, distribution, metabolism, etc.), the effects on liver and kidney systems, and whether it will cause harmful genetic recombination are not sufficiently deep $[114,115]$. A few studies have suggested that TDN is mainly excreted by the kidney [116-118], which may be detrimental to the accumulation of TDN in tumors. The biosafety of TDN and other DNA nanostructures will be the focus of future research. We believe that these explorations in immunostimulatory properties and pharmacokinetics as well as the actual conformation of branched DNA will provide better guidance for tumor suppression and immune surveillance in a more predictable manner.

Finally, at present, in vivo experiments related to TDN are still mainly conducted in mice, and there are still many challenges before conducting related experiments in humans. The main problem is the cost of production. For practical biomedical applications, high-purity functional DNA nanostructures must be produced in sufficient quantities. Several groups have reported convenient and cost-effective purification methods for DNA nanostructures at the laboratory level, but these methods have not been demonstrated on a larger scale. At present, the purification methods that have been reported for DNA nanostructures include agarose-gel-based separation method [119] and ultracentrifugation [120], and methods such as asymmetric PCR, RCA and fermentation are used to control costs and produce DNA in large quantities [120]. However, this remains a far cry from cheaper polymers. Improving the purity of DNA nanostructure, especially TDN, and reduce the cost is a practical problem that needs to be considered in the application.

\section{Conclusions}

Efficient drug carriers based on DNA nanostructures represent a promising goal of future research. Further increasing the yield of DNA nanostructures, exploring the mechanisms of cellular entry, overcoming biological barriers to improve cellular internalization, and controlling production costs are the major challenges. With the development of new strategies and technologies, including molecular design, assembly, and applications, we envision that DNA nanostructures will gain broader applicability as intelligent drug delivery carriers in the future.

\footnotetext{
Abbreviations

TDN: Tetrahedral DNA nanostructures; NDDSs: Nano-drug delivery systems; DNA: Deoxyribonucleic acid; 5-FU: 5-Fluorouracil; DOX: Doxorubicin; KLA: D-(KLAKLAK) $)_{2}$ P-gp: P-glycoprotein; BBB: Blood-brain barrier; EPR: Enhanced permeability and retention; EGFP: Enhanced green fluorescent protein; GSH: Glutathione; CPT: Camptothecin; anti-B2MG: $\beta$-2-Microglobulin; NIR: Near-infrared light; anti-EGFR: Anti-epidermal growth factor receptor; PDT:
} 
Photodynamic therapy; PS: Photosensitizer; ROS: Reactive oxygen species; MB: Methylene blue; CpG ODN: Cytosine-phosphate-guanine oligodeoxynucleotides; TNF-a: Tumor necrosis factor-a; IL-6: Interleukin-6; TLR9: Toll-like receptor 9; CpG: Cytosine-phosphate-guanine; PLK1: Polo-like kinase 1; SiRNAs: Small interfering RNAs; PEl: Polyethyleneimine; NLS: Nuclear localization signal peptide.

\section{Acknowledgements}

Reproduced from Ref. [42] with permission from the Royal Society of Chemistry.

\section{Authors' contributions}

YS and YL designed the article idea. JY and YL wrote the manuscript. XZ, ZZ, $\mathrm{KC}$ and $\mathrm{MW}$ collected and consulted literature. BH revised the manuscript. All authors read and approved the final manuscript.

\section{Funding}

The authors thank for the financial support of National Science Foundation of China (NSFC. 51803098) and China Postdoctoral Natural Science Foundation (No. 2021TQ0160).

\section{Availability of data and materials \\ Not applicable.}

\section{Declarations}

\section{Ethics approval and consent to participate}

Not applicable.

\section{Consent for publication}

Not applicable.

\section{Competing interests}

The authors declare that they have no competing interests.

\section{Author details}

'Department of Pharmaceutics, School of Pharmacy, Qingdao University, Qingdao 266021, China. ${ }^{2}$ National Engineering Research Center for Biomaterials, Sichuan University, Chengdu 610064, China. ${ }^{3}$ School of Biomedical Engineering, Sichuan University, Chengdu 610064, China. ${ }^{4}$ Department of Clinical Laboratory, Qingdao Special Servicemen Recuperation Centre of PLA Navy, Qingdao 266021, China. ${ }^{5}$ Department of Thoracic Surgery, Affiliated Hospital of Qingdao University, Qingdao 266000, China.

Received: 14 September 2021 Accepted: 24 November 2021

Published online: 07 December 2021

\section{References}

1. Daraee H, Etemadi A, Kouhi M, Alimirzalu S, Akbarzadeh A. Application of liposomes in medicine and drug delivery. Artif Cell Nanomed B. 2016:44:381-91.

2. Jiang L, Li L, He XD, Yi QY, He B, Cao J, Pan WS, Gu ZW. Overcoming drug-resistant lung cancer by paclitaxel loaded dual-functional liposomes with mitochondria targeting and $\mathrm{pH}$-response. Biomaterials. 2015:52:126-39.

3. Aziz ZABA, Ahmad A, Mohd-Setapar SH, Hassan H, Lokhat D, Kamal MA, Ashraf GM. Recent advances in drug delivery of polymeric nanomicelles. Curr Drug Metab. 2017;18:16-29.

4. Varde NK, Pack DW. Microspheres for controlled release drug delivery. Expert Opin Biol Ther. 2004;4:35-51.

5. Kaneshiro TL, Lu ZR. Targeted intracellular codelivery of chemotherapeutics and nucleic acid with a well-defined dendrimer-based nanoglobular carrier. Biomaterials. 2009;30:5660-6.

6. Ma D, Lin QM, Zhang LM, Liang YY, Xue W. A star-shaped porphyrinarginine functionalized poly(L-lysine) copolymer for photo-enhanced drug and gene co-delivery. Biomaterials. 2014:35:4357-67.

7. Hutter E, Fendler JH. Exploitation of localized surface plasmon resonance. Adv Mater. 2004:16:1685-706.
8. Xia XH, Yang MX, Oetjen LK, Zhang Y, Li QG, Chen JY, Xia YN. An enzyme-sensitive probe for photoacoustic imaging and fluorescence detection of protease activity. Nanoscale. 2011;3:950-3.

9. Mochalin VN, Shenderova O, Ho D, Gogotsi Y. The properties and applications of nanodiamonds. Nat Nanotechnol. 2012;7:11-23.

10. Baker SN, Baker GA. Luminescent carbon nanodots: emergent nanolights. Angew Chem Int Ed. 2010;49:6726-44.

11. Slowing II, Vivero-Escoto JL, Wu CW, Lin VSY. Mesoporous silica nanoparticles as controlled release drug delivery and gene transfection carriers. Adv Drug Deliv Rev. 2008;60:1278-88.

12. Cao C, Yang N, Zhao Y, Yang D, Hu Y, Yang D, Song X, Wang W, Dong $X$. Biodegradable hydrogel with thermo-response and hemostatic effect for photothermal enhanced anti-infective therapy. Nano Today. 2021:39: 101165

13. Yang D, Tu Y, Wang X, Cao C, Hu Y, Shao J, Weng L, Mou X, Dong X. A photo-triggered antifungal nanoplatform with efflux pump and heat shock protein reversal activity for enhanced chemo-photothermal synergistic therapy. Biomater Sci. 2021;9:3293-9.

14. Goodman RP, Schaap IAT, Tardin CF, Erben CM, Berry RM, Schmidt CF, Turberfield AJ. Rapid chiral assembly of rigid DNA building blocks for molecular nanofabrication. Science. 2005;310:1661-5.

15. Li J, Pei H, Zhu B, Liang L, Wei M, He Y, Chen N, Li D, Huang Q, Fan $\mathrm{CH}$. Self-assembled multivalent DNA nanostructures for noninvasive intracellular delivery of immunostimulatory $\mathrm{CpG}$ oligonucleotides. ACS Nano. 2011:5:8783-9.

16. Bergamini C, Angelini P, Rhoden KJ, Porcelli AM, Fato R, Zuccheri G. A practical approach for the detection of DNA nanostructures in single live human cells by fluorescence microscopy. Methods. 2014;67:185-92.

17. Charoenphol P, Bermudez H. Design and application of multifunctional DNA nanocarriers for therapeutic delivery. Acta Biomater. 2014;10:1683-91.

18. Goodman RP, Berry RM, Turberfield AJ. The single-step synthesis of a DNA tetrahedron. Chem Commun. 2004. https://doi.org/10.1039/B4022 93A.

19. Ma WJ, Zhan $Y X$, Zhang $Y X$, Xie XP, Mao CC, Lin YF. Enhanced neural regeneration with a concomitant treatment of framework nucleic acid and stem cells in spinal cord injury. ACS Appl Mater Interfaces. 2020:12:2095-106.

20. Carter MLJ, Rusling DA, Gurr S, Brown T, Fox KR. Stability of the different arms of a DNA tetrahedron and its interaction with a minor groove ligand. Biophys Chem. 2020;256: 106270.

21. Li SH, Sun Y, Tian TR, Oin X, Lin SY, Zhang T, Zhang Q, Zhou M, Zhang XL, Zhou Y, Zhao H, Zhu BF, Cai XX. MicroRNA-214-3p modified tetrahedral framework nucleic acids target survivin to induce tumour cell apoptosis. Cell Prolif. 2020;53:12708-21.

22. Shi SR, Yang C, Tian TR, Li SH, Lin SY, Zhang YX, Shao XR, Tao Z, Lin YF, Cai $X X$. Effects of tetrahedral framework nucleic acid/wogonin complexes on osteoarthritis. Bone Res. 2020;8:87-99.

23. Kim KR, Kim DR, Lee T, Yhee JY, Kim BS, Kwon IC, Ahn DR. Drug delivery by a self-assembled DNA tetrahedron for overcoming drug resistance in breast cancer cells. Chem Commun. 2013:49:2010-2.

24. Ozhalici-Unal $H$, Armitage BA. Fluorescent DNA nanotags based on a self-assembled DNA tetrahedron. ACS Nano. 2009:3:425-33.

25. Ding YS, Liu XT, Zhu J, Wang L, Jiang W. Quantitative single-molecule detection of protein based on DNA tetrahedron fluorescent nanolabels. Talanta. 2014;125:393-9.

26. Charoenphol P, Bermudez H. Aptamer-targeted DNA nanostructures for therapeutic delivery. Mol Pharm. 2014;11:1721-5.

27. Erben CM, Goodman RP, Turberfield AJ. Single-molecule protein encapsulation in a rigid DNA cage. Angew Chem Int Ed. 2006:45:7414-7.

28. Lee H, Lytton-Jean AKR, Chen Y, Love KT, Park Al, Karagiannis ED, Sehgal A, Querbes W, Zurenko CS, Jayaraman M, Peng CG, Charisse K, Borodovsky A, Manoharan M, Donahoe JS, Truelove J, Nahrendorf M, Langer $R$, Anderson DG. Molecularly self-assembled nucleic acid nanoparticles for targeted in vivo siRNA delivery. Nat Nanotechnol. 2012;7:389-93.

29. Kim KR, Kim HY, Lee YD, Ha JS, Kang JH, Jeong H, Bang D, Ko YT, Kim S, Lee H, Ahn DR. Self-assembled mirror DNA nanostructures for tumor-specific delivery of anticancer drugs. J Control Release. 2016:243:121-31. 
30. Thai HBD, Kim KR, Hong KT, Voitsitskyi T, Lee JS, Mao C, Ahn DR. Kidneytargeted cytosolic delivery of siRNA using a small-sized mirror DNA tetrahedron for enhanced potency. ACS Cent Sci. 2020;6:2250-8.

31. Xie X, Shao X, Ma W, Zhao D, Shi S, Li Q, Lin Y. Overcoming drug-resistant lung cancer by paclitaxel loaded tetrahedral DNA nanostructures. Nanoscale. 2018;10:5457-65

32. Wu TT, Liu JB, Liu MM, Liu SL, Zhao S, Tian R, Wei DS, Liu YZ, Zhao Y, Xiao $\mathrm{HH}$, Ding BQ. A nanobody-conjugated DNA nanoplatform for targeted platinum-drug delivery. Angew Chem Int Ed. 2019;58:14224-8.

33. Zhang J, Guo Y, Ding F, Pan G, Zhu X, Zhang C. A camptothecin-grafted DNA tetrahedron as a precise nanomedicine to inhibit tumor growth. Angew Chem Int Ed. 2019;58:13794-8.

34. Zhan Y, Ma W, Zhang Y, Mao C, Shao X, Xie X, Wang F, Liu X, Li Q, Lin $Y$. DNA-based nanomedicine with targeting and enhancement of therapeutic efficacy of breast cancer cells. ACS Appl Mater Interfaces. 2019;11:15354-65.

35. Mou Q, Ma Y, Pan G, Xue B, Yan D, Zhang C, Zhu X. DNA trojan horses: self-assembled floxuridine-containing DNA polyhedra for cancer therapy. Angew Chem Int Ed. 2017;56:12528-32.

36. Kim KR, Bang D, Ahn DR. Nano-formulation of a photosensitizer using a DNA tetrahedron and its potential for in vivo photodynamic therapy. Biomater Sci. 2016:4:605-9.

37. Liu ZC, Pei H, Zhang LM, Tian Y. Mitochondria-targeted DNA nanoprobe for real-time imaging and simultaneous quantification of $\mathrm{Ca}^{2+}$ and $\mathrm{pH}$ in neurons. ACS Nano. 2018;12:12357-68.

38. Setyawati MI, Kutty RV, Tay CY, Yuan X, Xie JP, Leong DT. Novel theranostic DNA nanoscaffolds for the simultaneous detection and killing of Escherichia coli and Staphylococcus aureus. ACS Appl Mater Interfaces. 2014;6:21822-31.

39. Setyawati MI, Kutty RV, Leong DT. DNA nanostructures carrying stoichiometrically definable antibodies. Small. 2016;12:5601-11.

40. Liu XW, Xu Y, Yu T, Clifford C, Liu Y, Yan H, Chang Y. A DNA nanostructure platform for directed assembly of synthetic vaccines. Nano Lett. 2012;12:4254-9.

41. Wong NY, Zhang C, Tan LH, Lu Y. Site-specific attachment of proteins onto a 3D DNA tetrahedron through backbone-modified phosphorothioate DNA. Small. 2011;7:1427-30.

42. Yan JQ, Chen J, Zhang N, Yang YD, Zhu WW, Li L, He B. Mitochondriatargeted tetrahedral DNA nanostructures for doxorubicin delivery and enhancement of apoptosis. J Mater Chem B. 2020;8:492-503.

43. Tian T, Li J, Xie C, Sun Y, Lei H, Liu X, Xia J, Shi J, Wang L, Lu W, Fan C. Targeted imaging of brain tumors with a framework nucleic acid probe. ACS Appl Mater Interfaces. 2018;10:3414-20.

44. Xia ZW, Wang P, Liu XW, Liu T, Yan YN, Yan J, Zhong J, Sun G, He DN. Tumor-penetrating peptide-modified DNA tetrahedron for targeting drug delivery. Biochemistry. 2016;55:1326-31.

45. Wu T, Liu Q, Cao Y, Tian R, Liu J, Ding B. Multifunctional double-bundle DNA tetrahedron for efficient regulation of gene expression. ACS App Mater Interfaces. 2020;12:32461-7.

46. Liang L, Li J, Li Q, Huang Q, Shi J, Yan H, Fan C. Single-particle tracking and modulation of cell entry pathways of a tetrahedral DNA nanostructure in live cells. Angew Chem Int Ed. 2014;53:7745-50.

47. Yan J, Zhang Z, Zhan X, Chen K, Pu Y, Liang Y, He B. In situ injection of dual-delivery PEG based MMP-2 sensitive hydrogels for enhanced tumor penetration and chemo-immune combination therapy. Nanoscale. 2021;13:9577-89.

48. Yang J, Jiang Q, He L, Zhan P, Liu Q, Liu S, Fu M, Liu J, Li C, Ding B. Selfassembled double-bundle DNA tetrahedron for efficient antisense delivery. ACS Appl Mater Interfaces. 2018;10:23693-9.

49. Tian TR, Xiao DX, Zhang T, Li YJ, Shi SR, Zhong WY, Gong P, Liu Z, Li Q, Lin YF. A framework nucleic acid based robotic nanobee for active targeting therapy. Adv Funct Mater. 2021;31:2007342-51.

50. Li Q, Zhao D, Shao X, Lin S, Xie X, Liu M, Ma W, Shi S, Lin Y. Aptamermodified tetrahedral DNA nanostructure for tumor-targeted drug delivery. ACS Appl Mater Interfaces. 2017;9:36695-701.

51. Kim K-R, Lee T, Kim B-S, Ahn D-R. Utilizing the bioorthogonal basepairing system of I-DNA to design ideal DNA nanocarriers for enhanced delivery of nucleic acid cargos. Chem Sci. 2014;5(1533):1537.

52. Liu M, Ma W, Li Q, Zhao D, Shao X, Huang Q, Hao L, Lin Y. Aptamertargeted DNA nanostructures with doxorubicin to treat protein tyrosine kinase 7-positive tumours. Cell Prolif. 2019;52: e12511.
53. Ren T, Deng ZW, Liu H, Li XF, Li JB, Yuan J, He Y, Liu Q, Yang YJ, Zhong SA. Co-delivery of DNAzyme and a chemotherapy drug using a DNA tetrahedron for enhanced anticancer therapy through synergistic effects. New J Chem. 2019;43:14020-7.

54. Keum JW, Ahn JH, Bermudez H. Design, assembly, and activity of antisense DNA nanostructures. Small. 2011;7:3529-35.

55. Zhou T, Wang Y, Dong Y, Chen C, Liu D, Yang Z. Tetrahedron DNA dendrimers and their encapsulation of gold nanoparticles. Bioorg Med Chem. 2014;22:4391-4.

56. Taylor Al, Beuron F, Peak-Chew SY, Morris EP, Herdewijn P, Holliger P. Nanostructures from synthetic genetic polymers. ChemBioChem. 2016;17:1107-10

57. Tian YQ, Huang YY, Gao P, Chen TF. Nucleus-targeted DNA tetrahedron as a nanocarrier of metal complexes for enhanced glioma therapy. Chem Commun. 2018;54:9394-7.

58. Zhang C, Su M, He Y, Leng Y, Ribbe AE, Wang G, Jiang W, Mao C. Exterior modification of a DNA tetrahedron. Chem Commun. 2010;46:6792-4.

59. Wang ZG, Xue QW, Tian WZ, Wang L, Jiang W. Quantitative detection of single DNA molecules on DNA tetrahedron decorated substrates. Chem Commun. 2012;48:9661-3.

60. Schlapak R, Danzberger J, Armitage D, Morgan D, Ebner A, Hinterdor fer P, Pollheimer P, Gruber HJ, Schaffler F, Howorka S. Nanoscale DNA ttrahedra improve biomolecular recognition on patterned surfaces. Small. 2012;8:89-97.

61. Pei H, Lu N, Wen YL, Song SP, Liu Y, Yan H, Fan CH. A DNA nanostructure-based biomolecular probe carrier platform for electrochemical biosensing. Adv Mater. 2010;22:4754.

62. Soundararajan S, Chen WW, Spicer EK, Courtenay-Luck N, Fernandes DJ. The nucleolin targeting aptamer AS1411 destabilizes bcl-2 messenger RNA in human breast cancer cells. Cancer Res. 2008;68:2358-65

63. Reyes-Reyes EM, Teng Y, Bates PJ. A new paradigm for aptamer therapeutic AS1411 action: uptake by macropinocytosis and its stimulation by a nucleolin-dependent mechanism. Cancer Res. 2010;70:8617-29.

64. Xu XH, Hamhouyia F, Thomas SD, Burke TJ, Girvan AC, McGregor WG, Trent JO, Miller DM, Bates PJ. Inhibition of DNA replication and induction of S phase cell cycle arrest by G-rich oligonucleotides. J Biol Chem. 2001;276:43221-30.

65. Minotti G, Menna P, Salvatorelli E, Cairo G, Gianni L. Anthracyclines: molecular advances and pharmacologic developments in antitumor activity and cardiotoxicity. Pharmacol Rev. 2004;56:185-229.

66. Zhang C, Li X, Tian C, Yu GM, Li YL, Jiang W, Mao CD. DNA nanocages swallow gold nanoparticles (AuNPs) to form AuNP@DNA cage coreshell structures. ACS Nano. 2014;8:1130-5.

67. Jain S, Hirst DG, O'Sullivan JM. Gold nanoparticles as novel agents for cancer therapy. Br J Radiol. 2012;85:101-13.

68. Xiao ZY, Ji CW, Shi JJ, Pridgen EM, Frieder J, Wu J, Farokhzad OC. DNA self-assembly of targeted near-infrared-responsive gold nanoparticles for cancer thermo-chemotherapy. Angew Chem Int Ed. 2012:51:11853-7.

69. Wang F, Wang YC, Dou S, Xiong MH, Sun TM, Wang J. Doxorubicintethered responsive gold nanoparticles facilitate intracellular drug delivery for overcoming multidrug resistance in cancer cells. ACS Nano. 2011:5:3679-92.

70. Yuan L, Giovanni M, Xie JP, Fan CH, Leong DT. Ultrasensitive IgG quantification using DNA nano-pyramids. NPG Asia Mater. 2014;6:e112.

71. Walsh AS, Yin HF, Erben CM, Wood MJA, Turberfield AJ. DNA cage delivery to mammalian cells. ACS Nano. 2011;5:5427-32.

72. Sacca B, Niemeyer CM. Functionalization of DNA nanostructures with proteins. Chem Soc Rev. 2011;40:5910-21.

73. Zhang T, Tian TR, Zhou RH, Li SH, Ma WJ, Zhang YX, Liu NX, Shi SR, Li QS, Xie XP, Ge YC, Liu MT, Zhang Q, Lin SY, Cai XX, Lin YF. Design, fabrication and applications of tetrahedral DNA nanostructure-based multifunctional complexes in drug delivery and biomedical treatment. Nat Protoc. 2020;15:2728-57.

74. Gratton SEA, Ropp PA, Pohlhaus PD, Luft JC, Madden VJ, Napier ME, DeSimone JM. The effect of particle design on cellular internalization pathways. Proc Natl Acad Sci USA. 2008;105:11613-8.

75. Keum JW, Bermudez H. DNA-based delivery vehicles: $\mathrm{pH}$-controlled disassembly and cargo release. Chem Commun. 2012;48:12118-20. 
76. Han D, Huang J, Zhu Z, Yuan QA, You MX, Chen Y, Tan WH. Molecular engineering of photoresponsive three-dimensional DNA nanostructures. Chem Commun. 2011:47:4670-2.

77. Pei H, Liang L, Yao GB, Li J, Huang Q, Fan CH. Reconfigurable threedimensional DNA nanostructures for the construction of intracellular logic sensors. Angew Chem Int Ed. 2012;51:9020-4.

78. Wang P, Xia ZW, Yan J, Liu XW, Yao GB, Pei H, Zuo XL, Sun G, He DN A study of $\mathrm{pH}$-dependence of shrink and stretch of tetrahedral DNA nanostructures. Nanoscale. 2015;7:6467-70.

79. Liu ZY, Li YM, Tian C, Mao CD. A smart DNA tetrahedron that isothermally assembles or dissociates in response to the solution $\mathrm{pH}$ value changes. Biomacromolecules. 2013;14:1711-4.

80. Kim SH, Kim KR, Ahn DR, Lee JE, Yang EG, Kim SY. Reversible regulation of enzyme activity by pH-responsive encapsulation in DNA nanocages. ACS Nano. 2017;11:9352-9.

81. Dong Y, Yao C, Zhu Y, Yang L, Luo D, Yang D. DNA functional materials assembled from branched DNA: design, synthesis, and applications. Chem Rev. 2020;120:9420-81.

82. Endo M, Majima T. Control of a double helix DNA assembly by use of cross-linked oligonucleotides. J Am Chem Soc. 2003;125:13654-5.

83. Qu AH, Wu XL, Li S, Sun MZ, Xu LG, Kuang H, Xu CL. An NIR-responsive DNA-mediated nanotetrahedron enhances the clearance of senescent cells. Adv Mater. 2020;32:184-93.

84. Mo R, Jiang TY, Sun WJ, Gu Z. ATP-responsive DNA-graphene hybrid nanoaggregates for anticancer drug delivery. Biomaterials. 2015;50:67-74.

85. Shen YZ, Tian Q, Sun YD, Xu JJ, Ye DJ, Chen HY. ATP-activatable photosensitizer enables dual fluorescence imaging and targeted photodynamic therapy of tumor. Anal Chem. 2017;89:13610-7.

86. Oh SS, Plakos K, Xiao Y, Eisenstein M, Soh HT. In vitro selection of shapechanging DNA nanostructures capable of binding-induced cargo release. ACS Nano. 2013;7:9675-83.

87. Mo R, Jiang TY, DiSanto R, Tai WY, Gu Z. ATP-triggered anticancer drug delivery. Nat Commun. 2014;5:3364-73.

88. Abi A, Lin MH, Pei H, Fan CH, Ferapontova EE, Zuo XL. Electrochemical switching with 3D DNA tetrahedral nanostructures self-assembled at gold electrodes. ACS Appl Mater Inter. 2014;6:8928-31.

89. Goodman RP, Heilemann M, Doose S, Erben CM, Kapanidis AN, Turberfield AJ. Reconfigurable, braced, three-dimensional DNA nanostructures. Nat Nanotechnol. 2008;3:93-6.

90. Zhang C, Tian C, Li X, Qian H, Hao CH, Jiang W, Mao CD. Reversibly switching the surface porosity of a DNA tetrahedron. J Am Chem Soc. 2012;134:11998-2001.

91. Rottenberg S, Disler C, Perego P. The rediscovery of platinum-based cancer therapy. Nat Rev Cancer. 2020;21:37-50.

92. Adamsen $\mathrm{BL}$, Kravik KL, De Angelis PM. DNA damage signaling in response to 5-fluorouracil in three colorectal cancer cell lines with different mismatch repair and TP53 status. Int J Oncol. 2011;39:673-82.

93. Hsiang YH, Hertzberg R, Hecht S, Liu LF. Camptothecin induces proteinlinked DNA breaks via mammalian DNA topoisomerase-I. J Biol Chem. 1985:260:4873-8.

94. Schiff PB, Fant J, Horwitz SB. Promotion of microtubule assembly in vitro by Taxol. Nature. 1979;277:665-7.

95. Yan J, Zhang N, Zhang Z, Zhu W, Li B, Li L, Pu Y, He B. Redox-responsive polyethyleneimine/tetrahedron DNA/doxorubicin nanocomplexes for deep cell/tissue penetration to overcome multidrug resistance. J Control Release. 2020;329:36-49.

96. He Y, Ye T, Su M, Zhang C, Ribbe AE, Jiang W, Mao C. Hierarchical selfassembly of DNA into symmetric supramolecular polyhedra. Nature. 2008:452:198-201.

97. Chang KW, Tang Y, Fang XF, Yin SY, Xu H, Wu CF. Incorporation of porphyrin to $\pi$-conjugated backbone for polymer-dot-sensitized photodynamic therapy. Biomacromol. 2016;17:2128-36.

98. Zhuang XX, Ma XW, Xue XD, Jiang $Q$, Song LL, Dai LR, Zhang $C Q$, Jin SB, Yang KN, Ding BQ, Wang PC, Liang XJ. A photosensitizer-loaded DNA origami nanosystem for photodynamic therapy. ACS Nano. 2016;10:3486-95.

99. Dougherty TJ, Gomer CJ, Henderson BW, Jori G, Kessel D, Korbelik M, Moan J, Peng Q. Photodynamic therapy. JNCl. 1998;90:889-905.

100. Dolmans D, Fukumura D, Jain RK. Photodynamic therapy for cancer. Nat Rev Cancer. 2003:3:380-7.
101. Park J, Jiang Q, Feng DW, Mao LQ, Zhou HC. Size-controlled synthesis of porphyrinic metal-organic framework and functionalization for targeted photodynamic therapy. J Am Chem Soc. 2016;138:3518-25.

102. Latz E, Verma A, Visintin A, Gong M, Sirois CM, Klein DCG, Monks BG, McKnight CJ, Lamphier MS, Duprex WP, EspevikT, Golenbock DT. Ligand-induced conformational changes allosterically activate Toll-like receptor 9. Nat Immunol. 2007:8:772-9.

103. Krieg AM. CpG motifs in bacterial DNA and their immune effects. Annu Rev Immunol. 2002;20:709-60.

104. Hemmi H, Takeuchi O, Kawai T, Kaisho T, Sato S, Sanjo H, Matsumoto M, Hoshino K, Wagner H, Takeda K, Akira S. A Toll-like receptor recognizes bacterial DNA. Nature. 2000:408:740-5.

105. Klinman DM. Immunotherapeutic uses of CpG oligodeoxynucleotides. Nat Rev Immunol. 2004:4:248-57.

106. Liu JB, Wu TT, Lu XH, Wu XH, Liu SL, Zhao S, Xu XH, Ding BQ. A selfassembled platform based on branched DNA for sgRNA/Cas9/antisense delivery. J Am Chem Soc. 2019;141:19032-7.

107. Wen AM, Steinmetz NF. Design of virus-based nanomaterials for medicine, biotechnology, and energy. Chem Soc Rev. 2016;45:4074-126.

108. Tian T, Zhang T, Zhou T, Lin S, Shi S, Lin Y. Synthesis of an ethyleneimine/ tetrahedral DNA nanostructure complex and its potential application as a multi-functional delivery vehicle. Nanoscale. 2017;9:18402-12.

109. Ge Y, Tian T, Shao X, Lin S, Zhang T, Lin Y, Cai X. PEGylated protaminebased adsorbing improves the biological properties and stability of tetrahedral framework nucleic acids. ACS Appl Mater Inter. 2019;11:27588-97.

110. Godbey WT, Wu KK, Mikos AG. Poly(ethylenimine) and its role in gene delivery. J Control Release. 1999;60:149-60.

111. Chen W, Zhong P, Meng FH, Cheng R, Deng C, Feijen J, Zhong ZY. Redox and $\mathrm{pH}$-responsive degradable micelles for dually activated intracellular anticancer drug release. J Control Release. 2013;169:171-9.

112. Hu QQ, Li H, Wang LH, Gu HZ, Fan CH. DNA nanotechnology-enabled drug delivery systems. Chem Rev. 2019;119:6459-506.

113. Yu JW, Liu ZY, Jiang W, Wang GS, Mao CD. De novo design of an RNA tile that self-assembles into a homo-octameric nanoprism. Nat Commun. 2015:6:1-6.

114. Cavalier-Smith T. Nuclear volume control by nucleoskeletal DNA, selection for cell volume and cell growth rate, and the solution of the DNA C-value paradox. J Cell Sci. 1978;34:247-78.

115. Gregory TR. Coincidence, coevolution, or causation? DNA content, cell size, and the C-value enigma. Biol Rev. 2001;76:65-101.

116. Jiang D, Rosenkrans ZT, Ni D, Lin J, Huang P, Cai W. Nanomedicines for renal management: from imaging to treatment. Acc Chem Res. 2020;53:1869-80.

117. Jiang D, Im HJ, Boleyn ME, England CG, Ni D, Kang L, Engle JW, Huang P, Lan X, Cai W. Efficient renal clearance of DNA tetrahedron nanoparticles enables quantitative evaluation of kidney function. Nano Res. 2019;12:637-42.

118. Jiang D, Sun Y, Li J, Li Q, Lv M, Zhu B, Tian T, Cheng D, Xia J, Zhang L, Wang L, Huang Q, Shi J, Fan C. Multiple-armed tetrahedral DNA nanostructures for tumor-targeting, dual-modality in vivo imaging. ACS Appl Mater Interfaces. 2016;8:4378-84.

119. Bellot G, McClintock MA, Lin CX, Shih WM. Recovery of intact DNA nanostructures after agarose gel-based separation. Nat Methods. 2011:8:192-4.

120. Lin CX, Perrault SD, Kwak M, Graf F, Shih WM. Purification of DNAorigami nanostructures by rate-zonal centrifugation. Nucleic Acids Res. 2013:41:40-5.

\section{Publisher's Note}

Springer Nature remains neutral with regard to jurisdictional claims in published maps and institutional affiliations. 